\title{
HIV infection and related risk behaviours among female sex workers in greater Cairo, Egypt
}

\author{
I.A. Kabbash, ${ }^{7}$ I. Abdul-Rahman, ${ }^{2}$ Y.A. Shehata ${ }^{3}$ and A.A-R. Omar ${ }^{1}$
}

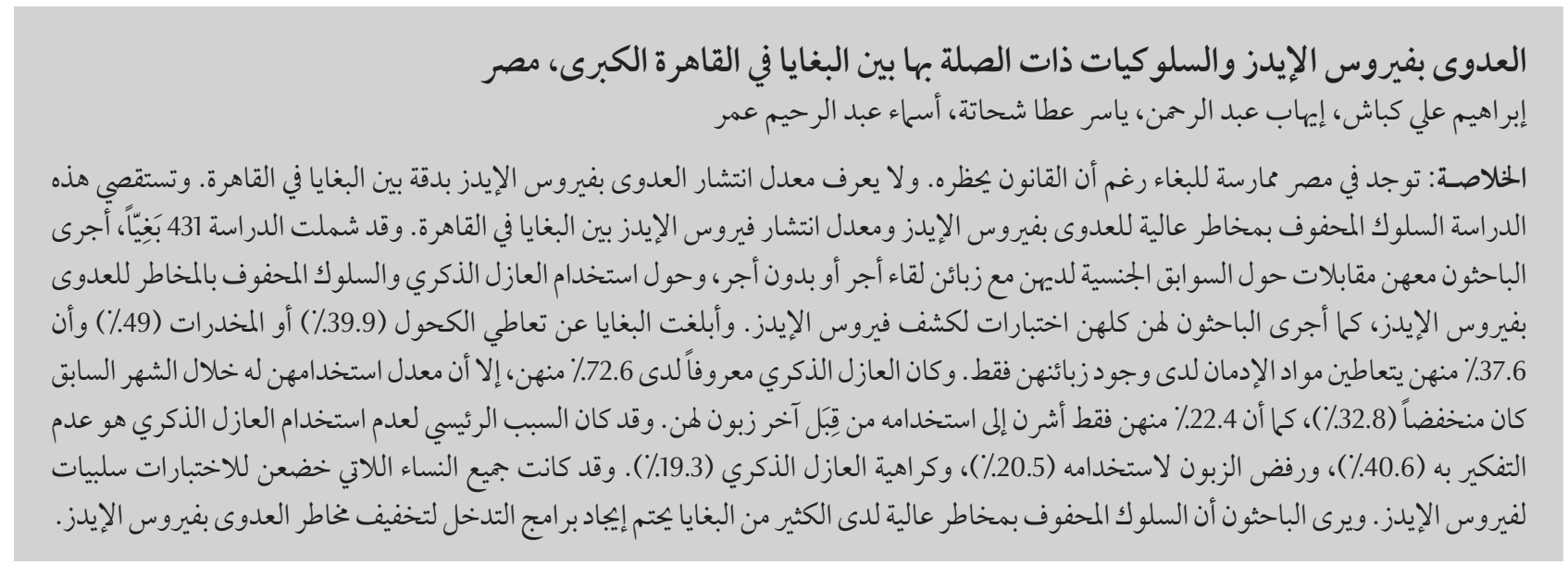

ABSTRACT Although illegal in Egypt, prostitution exists. The prevalence of HIV infection among female sex workers (FSWs) in Cairo is not precisely known. This cross-sectional study investigated the high-risk behaviour for HIV infection and HIV prevalence among FSWs in greater Cairo. A total of 431 FSWs were interviewed about their sexual history with paid and unpaid partners, condom use and risky behaviour for HIV infection; all were tested for HIV. Use of alcohol and drugs was reported by $39.9 \%$ and $49.0 \%$ of the women respectively; $37.6 \%$ only used such substances while with a client. Male condoms were known by $72.6 \%$ but their use in the previous month was low (32.8\%) and only $22.4 \%$ had used one with their last client. The main reasons for not using condoms were not thinking of it (40.6\%) and client refusal (20.5\%). All the women tested negative for HIV infection. The high-risk behaviour of many FSWs necessitates intervention programmes to reduce their risk of HIV infection.

Infection à VIH et comportements à risque associés chez les professionnelles du sexe dans le Grand Caire (Égypte)

RÉSUMÉ Bien qu'illégale en Égypte, la prostitution existe. La prévalence de l'infection à VIH chez les professionnelles du sexe au Caire n'est pas connue précisément. La présente étude transversale a étudié les comportements associés à un risque important de contracter une infection à VIH et la prévalence de ce virus chez les professionnelles du sexe en activité dans le Grand Caire. Au total, 431 professionnelles du sexe ont été interrogées au sujet de leurs antécédents en matière de rapports sexuels avec des partenaires rémunérant ou non leurs services, d'utilisation du préservatif et de comportements à risque pour l'infection à VIH; toutes les personnes interrogées ont été soumises à un test de dépistage du VIH. Parmi celles-ci, 39,9\% déclaraient consommer de l'alcool et 49,0\% de la drogue ; $37,6 \%$ en consommaient uniquement avec leurs clients. Les préservatifs masculins étaient connus de 72,6\% d'entre elles mais elles étaient peu nombreuses (32,8 \%) à en avoir utilisé au cours du mois précédent et seulement 22,4 \% en avaient utilisé un avec leur dernier client. Les principales raisons de leur absence d'utilisation des préservatifs étaient I'oubli (40,6\%) et le refus du client (20,5\%). Toutes les professionnelles du sexe de l'étude ont obtenu des résultats négatifs dans le dépistage du VIH. Le comportement à haut risque de nombreuses professionnelles du sexe appelle des programmes d'intervention afin de réduire leur risque d'infection à VIH.

'Department of Public Health and Community Medicine, Faculty of Medicine, Tanta University, Tanta, Egypt (Correspondence to I.A. Kabbash: iafkabbash@gmail.com). ${ }^{2}$ National AIDS Control Programme, Ministry of Health and Population, Cairo, Egypt. ${ }^{3}$ Department of Public Health and Community Medicine, Faculty of Medicine, Menoufiya University, Menoufiya, Egypt.

Received: 18/05/11; accepted: 21/08/11 


\section{Introduction}

Worldwide, commercial sex workers are considered one of the most at-risk groups, including for HIV infection [1]. Sex workers frequently have insufficient access to adequate health services, male and female condoms and other preventive services [2].

The extent of HIV infection among female sex workers (FSWs) in Greater Cairo, Egypt, is not precisely known due to the fact that few field studies have been undertaken and therefore a scarcity of data. Conducting studies among female sex workers can be problematic because of the stigma related to sex work. That said, the prevalence of HIV infection in Greater Cairo still appears to be lower than that in other industrialized cities [3]. Worldwide studies estimate that nearly 5 million people are being infected with HIV every year $[4,5]$ and about half of those currently infected with HIV are females [5]. Rates of HIV infection are higher among those involved with sex work than in most other populations [2].

The number of FSWs has been increasing over the past 2 decades mainly for economic reasons [5-7]. Many studies indicate that the risk of getting infected with HIV is high among FSWs and their clients [8]. Paid sex remains an important factor in many of the HIV epidemics in western, central and eastern Africa. It is estimated that $32 \%$ of new HIV infections in Ghana, 14\% in Kenya and $10 \%$ in Uganda are linked to sex work (HIV infection among sex workers, their clients, or their other sex partners) [9].

In Egypt, commercial sex is illegal but it does exist. This study aimed to determine the prevalence of HIV infection among FSWs in Greater Cairo, Egypt, and identify the HIV-related risk behaviours among them.

\section{Methods}

\section{Setting and subjects}

The study was conducted in Greater Cairo which includes 3 Governorates: Cairo, Giza and Qualiobia. This cosmopolitan area accommodates a population of nearly 14 million people [10]. Places of gathering of FSWs were identified through focus groups discussions with FSWs and with El-Shehab nongovernmental organization (NGO) working with FSWs.

The target population was FSWs representing different categories as identified by 3 focus group discussions that were conducted before starting the field work. Each focus group included 6-8 sex workers recruited by El-Shehab organization. The focus group discussions identified the different categories of FSWs and the main places they gathered. These were: Street FSWs; FSWs at bars and night clubs; Dancers; FSWs at brothels; FSWs at coffeehouses; FSWs at hotels.

The sample size was based on the calculation: $n=Z_{a 0.95} \times[p \times(1-p)] / d^{2}$, where $p=$ prevalence of HIV infection among FSWs, estimated to be $0.3 \%$ and $\mathrm{d}=$ expected margin of error $(3 \%)$. Thus the total sample size was estimated at 234. We increased this number to 431 FSWs to ensure adequate representation of all categories.

A list of places where sex workers tended to gather was prepared based on information gained from focus group discussions and the experience of field work done by El-Shehab. One place for each category was randomly selected (a street, night club/bar, hair dresser where dancer gather to prepare for work, a brothel and a coffee shop). Sex workers at hotels were difficult to access as we did not succeed in getting approval from hotel authorities to conduct field work there, so they had to be omitted from in the study.

\section{Data collection and tools}

This work was conducted during the period from August 2009 to end of April 2010.

Data were collected by a questionnaire which was adapted from the questionnaire published by family health international [11]. It was translated into Arabic and some modifications were made to make it suitable for the situation of sex work in Egypt. Modifications were done based on the experience of the research team and in consultation with experts working previously with this group from El-Shehab. The questionnaire included questions covering the following:

- Sexual practices of FSWs

- HIV-related risk behaviour

- Knowledge and practice of FSWs of male condoms.

A pilot study was conducted with a sample of sex workers who were not included in the main study in order to test the questionnaire and ensure its feasibility for the study.

Data were collected through interview of the participants by 6 trained former sex workers who worked with ElShehab outreach programme for harm reduction for HIV infection among sex workers in different regions of greater Cairo. The data collectors were directed to the locations to collect data from all those available at the time of interview. The process was repeated and another group of locations was randomly chosen and visited until the desired sample size was obtained. For each category the suitable timing for visiting the place was identified to ensure cooperation of the study participants and avoid interfering with their work needs. A suitable place, which offered comfortable conditions and confidentiality, was chosen by the data collectors to conduct the interview. The rate of refusal by the target population was $3 \%$. Financial incentives were given to the sex workers who participated in the study to compensate for 
the time lost during the interview. This incentive helped to minimize the rate for refusal.

Blood samples were also taken from each participant for HIV testing carried out using an ELISA method. The blood samples were taken by female workers trained in blood sampling who accompanied the data collector teams during the field work. None of the FSWs refused to give a sample.

\section{Analysis}

The collected data were organized, tabulated and statistically analysed using SPSS, version 17.

\section{Ethical considerations}

Data collection was anonymous. Confidentiality was ensured whereby no data were linked to names or specific persons. No pressure of any kind was used to recruit the study participants. The study objectives and contents of the questionnaire were explained to the participants before starting data collection. Witnessed (by the data collectors), informed verbal consent was taken before the interview and blood sampling. The collected data were only used for research purposes according to the objectives of the study and for the benefit of the participants.

\section{Results}

A total of $431 \mathrm{FSW}$ sere included in the study. Their mean age was 29.38 [standard deviation (SD) 9.48] years and median age 27 years. Almost $61 \%$ had attended school with a mean duration of 10 years. The majority (65.9\%) were ever or currently married during the study period. Over half of the participants (58.7\%) first had sex in exchange of money or some other benefits between the ages of 15 and 25 years, with a mean age of 22.28 (SD 6.66) years. The mean duration of working as a sex worker was 6.32 (SD 6.42) years. Monthly income from sex work was reported as < US\$ 100 by $29.2 \%$ of the women while $57.5 \%$ reported a monthly income ranging between US\$ 100 and 500 (Table 1).

Nearly $40 \%$ admitted drinking alcohol, $7 \%$ daily and $32.9 \%$ occasionally. Drug use was reported by $49 \%$ of the women, which was mostly hashish (96.2\%), and $37.6 \%$ of drug use was reported to be associated with sexual practices, i.e. they used drugs only when with a client. Injecting drug use was reported by $5.6 \%$ in the last year. The majority (61\%) of the women reported freedom to choose clients while $8.1 \%$ never had this chance. Over one-third (35.3\%) reported experiencing sexual violence, either the threat of violence to have sex or violence during sex, which was mostly physical as reported by $73.7 \%$. Abnormal vaginal discharge in the last year was reported by $76.1 \%$ of the women while $15.5 \%$ reported suffering of genital ulcers (Table 2).

Having unpaid sexual partners was reported by $59.2 \%$ of the women; these were husbands $(30.6 \%)$ or boyfriends
(21.6\%). Of the participants with unpaid partners, 38.4\% reported that their partners had a spouse or other sexual partners. The number of times to have had sex with their unpaid partner in the month before data collection was $1-5$ times for $48.6 \%$ of the women while $22.8 \%$ reported 10 or more times. Of the 255 women with unpaid partners, $29.4 \%$ reported abuse was used for sexual relations by the unpaid partner, which was mainly physical (74.7\%). Use of drugs by unpaid partners was reported by $70.6 \%$ of the women, $10.6 \%$ of whom injected drugs (Table 3 ).

Most of studied sexworkers (72.6\%) knew about male condoms. However, only $22.4 \%$ had used them with the last client and $32.8 \%$ had used them in the past month. Their use was at the suggestion of the sex worker, as reported by $51.5 \%$ of the women who used a condom with their last client, while $37.1 \%$ reported that the client asked for condom use. The main reasons for not using male condom were not thinking about it (40.6\%), client refused (20.5\%),

\begin{tabular}{|c|c|}
\hline Characteristic & Value \\
\hline \multicolumn{2}{|l|}{ Age (years) } \\
\hline Mean (SD) & $29.38(9.48)$ \\
\hline Median & 27.00 \\
\hline \multicolumn{2}{|l|}{ Attended school } \\
\hline Yes [No. (\%)] & $262(60.8)$ \\
\hline Mean (SD) no. of years at school & $10.18(3.24)$ \\
\hline Median no. of years at school & 10 \\
\hline Married, now or previously [No. (\%)] & $283(65.7)$ \\
\hline Mean (SD) age at first selling sex (years) & $22.28(6.66)$ \\
\hline \multicolumn{2}{|l|}{ Duration of sex work (years) } \\
\hline Range & $1-35$ \\
\hline Mean (SD) & $6.32(6.42)$ \\
\hline Median & 4.0 \\
\hline \multicolumn{2}{|l|}{ Monthly income (US\$) [No. (\%)] } \\
\hline$<100$ & $126(29.2)$ \\
\hline $100-$ & $158(36.6)$ \\
\hline $200-$ & $90(20.9)$ \\
\hline $500+$ & $45(10.4)$ \\
\hline Unidentified & $12(2.8)$ \\
\hline
\end{tabular}

$S D=$ standard deviation. 


\begin{tabular}{|c|c|c|}
\hline Variable & No. $(n=431)$ & $\%$ \\
\hline \multicolumn{3}{|l|}{ Alcohol intake in the last month } \\
\hline Daily & 30 & 7.0 \\
\hline At least once weekly & 70 & 16.2 \\
\hline 2-3 times monthly & 72 & 16.7 \\
\hline None & 259 & 60.1 \\
\hline \multicolumn{3}{|l|}{ Drug use } \\
\hline Used drugs $^{\mathrm{a}}$ & 211 & 49.0 \\
\hline Injecting drugs in the last year & 24 & 5.6 \\
\hline Use of drugs associated with sex & 162 & 37.6 \\
\hline \multicolumn{3}{|l|}{ Freedom to choose clients } \\
\hline Always & 263 & 61.0 \\
\hline Most of the time & 50 & 11.6 \\
\hline Sometimes & 52 & 12.1 \\
\hline Rarely & 31 & 7.2 \\
\hline Never & 35 & 8.1 \\
\hline \multicolumn{3}{|l|}{ Experienced sexual violence ${ }^{b}$} \\
\hline Many times & 26 & 6.0 \\
\hline Sometimes & 28 & 6.5 \\
\hline Few times & 98 & 22.7 \\
\hline Never & 279 & 64.7 \\
\hline \multicolumn{3}{|l|}{ Type of violence $(n=152)$} \\
\hline Physical & 112 & 73.7 \\
\hline Verbal & 7 & 4.6 \\
\hline Both & 33 & 21.7 \\
\hline \multicolumn{3}{|c|}{ Sexual health issues in the past 12 months } \\
\hline Unusual vaginal discharge & 328 & 76.1 \\
\hline Genital ulcers & 67 & 15.5 \\
\hline
\end{tabular}

${ }^{a} 96.2 \%$ of reported drug use was cannabis.

${ }^{b}$ Either the threat of violence to have sex or violence during sex.

do not like it (19.3\%) and using another contraceptive method (13.5\%). Condom use during every a sexual relation during last month was reported by only $7.7 \%$ while $67.2 \%$ reported never using condoms in the previous month (Table 4).

Condom use with unpaid sexual partners was reported by $24.2 \%$ of the women which was at the recommendation of the sex worker in $58.8 \%$ of cases and of the sexual partner in $29.4 \%$. Use of condom was "never thought of it" by $37.7 \%$ of the women, while $17.8 \%$ had no reason, $17.3 \%$ did not like condoms and for $15.2 \%$ the unpaid sexual partner refused. Most sex workers (76.3\%) reported never using a condom with while having sex during menstruation. Only $7.7 \%$ reported practising group sex and of these $21.2 \%$ reported using condoms while having group sex ( $\mathrm{Ta}$ ble 6).

All the FSWs tested negative for HIV infection, giving a $0 \%$ prevalence of HIV infection.

\section{Discussion}

Our results show that the behaviours of FSWs in Cairo put them at risk of HIV infection. These include: alcohol intake, drug abuse, physical violence, inadequate use of protective measures, questionable self-efficacy in using condoms, and having sex during menstruation.

Although alcohol intake among Egyptians is extremely low (less than $0.2 \%$ of males, and less than $0.01 \%$ of females) [12], alcohol intake was prevalent among FSWs in this study; nearly $40 \%$ reported drinking alcohol. At the same time, drug use was reported by nearly a half of the FSWs, most commonly smoking hashish (cannabis), which parallels the fact that hashish is the most commonly abused drug in Egypt [13]. Injecting drugs was relatively low (5.6\%). This is comparable to findings of a study in London showing drug injection to be $13 \%$ among FSWs [14]. Most of these FSWs had commercial and non-commercial (unpaid) partners and some of these unpaid partners abused drugs by injection $[14,15]$. Nearly $60 \%$ of FSWs in our study were having sex with unpaid partners $70.6 \%$ of whom abused drugs and $10.6 \%$ were injecting drugs. This exposes FSWs to an additional HIV-risk, as drug intoxication alters the users' mental status and judgement, which, in turn, can increase the likelihood that they will engage in high-risk sexual behaviours.

Violence against FSWs is widespread and it is committed by clients, controllers, managers of sex work establishments and intimate partners [2]. 


\begin{tabular}{|c|c|c|}
\hline Variable & No. & $\%$ \\
\hline \multicolumn{3}{|l|}{ Unpaid sexual partners during last 6 months $(n=431)$} \\
\hline Husband & 132 & 30.6 \\
\hline Boyfriend & 93 & 21.6 \\
\hline Multiple boyfriends & 28 & 6.5 \\
\hline Girlfriend & 2 & 0.5 \\
\hline None & 176 & 40.8 \\
\hline Unpaid partner has another sexual partner (spouse or other) $(n=255)$ & 98 & 38.4 \\
\hline \multicolumn{3}{|c|}{ Average daily number of sexual relations last month with unpaid partner $(n=255)$} \\
\hline 0 & 12 & 4.7 \\
\hline $1-$ & 124 & 48.6 \\
\hline $5-$ & 61 & 23.9 \\
\hline $10-$ & 31 & 12.2 \\
\hline$>15$ & 27 & 10.6 \\
\hline \multicolumn{3}{|l|}{ Experienced sexual violence $^{a}(n=255)$} \\
\hline Many times & 17 & 6.7 \\
\hline Sometimes & 20 & 7.8 \\
\hline Few times & 38 & 14.9 \\
\hline Never & 180 & 70.6 \\
\hline \multicolumn{3}{|l|}{ Type of violence $(n=75)$} \\
\hline Physical & 56 & 74.7 \\
\hline Verbal & 3 & 4.0 \\
\hline Both & 16 & 21.3 \\
\hline \multicolumn{3}{|l|}{ Unpaid partner's drug use } \\
\hline Uses drugs $(n=255)$ & 180 & 70.6 \\
\hline Injects drugs $(n=180)$ & 19 & 10.6 \\
\hline
\end{tabular}

${ }^{a}$ Either the threat of violence to have sex or violence during sex.

The same finding was obtained in our study where more than one-third of the studied sex workers reported having sex under the threat of abuse or abusive sex, which was mostly physical. Violence is associated with unprotected sex and increases the risk of HIV infection due to vaginal trauma and lacerations resulting from the use of force $[2,15-18]$.

Sexually transmitted infections (STIs) are common among FSWs as shown by different studies [19-21]. However, the prevalence of such infections differs from one study to another based on the circumstances of sex work organization and whether it is legal or illegal $[14,15]$. In the present study abnormal vaginal discharge suggestive of STIs was reported by the majority of the FSWs as well as genital ulcers, at a lower prevalence. Individuals who are infected with STIs are 5-10 times more likely than uninfected individuals to acquire or to transmit HIV through sexual contact. The breaking of the genital tract lining creates a portal of entry for HIV, and HIV infected individuals with other STIs are more likely to shed HIV in their genital secretions [19].

Condoms are one of the most effective methods to prevent sexual transmission of HIV infection and other STIs. They should be readily available for sex workers and their clients [2]. Studies among FSWs show different rates of condom use in different countries. Condoms were always used by 93.4\% of FSWs in Santiago, Chile [22],
$44 \%$ in Calcutta, India [1] and $98 \%$ in London, UK [14]. Many reasons were given for not using a male condom including never having thought of it, client refusal, dislike of condoms and using another contraceptive method. Condom use among the women in our study was relatively lower with their unpaid partners. FSWs did not perceive the risk of HIV infection from their intimate unpaid partners in spite of our finding that these partners usually abused drugs and had other sexual partners. The same finding of low condom use with unpaid partners has been documented in other similar studies. [14,20,23]. Among a minority of the sex workers in our study reporting use of a condom with the last client, self-efficacy of condom use was questionable among those who experienced condom tear as almost 


\begin{tabular}{|c|c|c|}
\hline Variable & No. & $\%$ \\
\hline Ever heard about male condom $(n=431)$ & 313 & 72.6 \\
\hline \multicolumn{3}{|l|}{ Use of condoms with clients } \\
\hline Used a condom in the past month $(n=313)$ & 102 & 32.6 \\
\hline Used a condom with last client $(n=313)$ & 70 & 22.4 \\
\hline \multicolumn{3}{|l|}{ Person recommending male condom use $(n=70)$} \\
\hline Sex worker & 36 & 51.5 \\
\hline Client & 26 & 37.1 \\
\hline Both & 8 & 11.4 \\
\hline \multicolumn{3}{|l|}{ Reasons for not using male condom $(n=243)^{a}$} \\
\hline Unavailable & 11 & 4.5 \\
\hline It is expensive & 2 & 0.8 \\
\hline Client refusal & 50 & 20.5 \\
\hline Don't like it & 47 & 19.3 \\
\hline Using other contraceptive methods & 33 & 13.5 \\
\hline Not necessary to use it & 11 & 4.5 \\
\hline Never thought of it & 99 & 40.6 \\
\hline Don't know & 13 & 5.3 \\
\hline Other reasons & 31 & 12.7 \\
\hline \multicolumn{3}{|c|}{ Frequency of male condom use in the last month with clients $(n=311)$} \\
\hline Every time & 24 & 7.7 \\
\hline Almost all the time & 28 & 9.0 \\
\hline Sometimes & 50 & 16.1 \\
\hline Never & 209 & 67.2 \\
\hline
\end{tabular}

${ }^{a}$ Not mutually exclusive.

\begin{tabular}{|c|c|c|}
\hline Variable & No. & $\%$ \\
\hline Ever used a condom with unpaid sexual partner $(n=252)$ & 61 & 24.2 \\
\hline Used a condom during the last sexual act with unpaid sexual partner $(n=253)$ & 34 & 13.4 \\
\hline \multicolumn{3}{|l|}{ Person recommending condom use $(n=34)$} \\
\hline Sex worker & 20 & 58.8 \\
\hline Sexual partner & 10 & 29.4 \\
\hline Both & 4 & 11.8 \\
\hline \multicolumn{3}{|l|}{ Reason for not using condom $(n=191)^{a}$} \\
\hline Condom unavailable & 2 & 1.0 \\
\hline Expensive & 0 & 0.0 \\
\hline Partner refused & 29 & 15.2 \\
\hline Don't like it & 33 & 17.3 \\
\hline Using other contraceptive methods & 23 & 12.0 \\
\hline Not necessary to use it & 9 & 4.7 \\
\hline Did not consider using it & 72 & 37.7 \\
\hline Don't know & 34 & 17.8 \\
\hline Other reasons & 24 & 12.6 \\
\hline \multicolumn{3}{|l|}{$\begin{array}{l}\text { Frequency of male condom use during last month ith unpaid sexual } \\
\text { partner }(n=253)\end{array}$} \\
\hline Every time & 10 & 4.0 \\
\hline Almost all the time & 16 & 6.3 \\
\hline Sometimes & 34 & 13.4 \\
\hline Never & 193 & 76.3 \\
\hline
\end{tabular}

${ }^{a}$ Not mutually exclusive. 


\begin{tabular}{|c|c|c|}
\hline \multicolumn{3}{|c|}{$\begin{array}{l}\text { Table } 6 \text { Distribution of studied female sex workers in relation to their knowledge } \\
\text { about male condoms }\end{array}$} \\
\hline Variable & No. & $\%$ \\
\hline \multicolumn{3}{|c|}{ Places where condoms can be obtained $(n=424)$} \\
\hline Pharmacies & 315 & 74.3 \\
\hline Supermarkets & 1 & 0.2 \\
\hline Clinics & 4 & 0.9 \\
\hline Hospitals & 14 & 3.3 \\
\hline Bars/hotels & 3 & 0.7 \\
\hline From a friend & 15 & 3.5 \\
\hline Nongovernmental organizations & 23 & 5.4 \\
\hline Don't know & 100 & 23.6 \\
\hline \multicolumn{3}{|l|}{ Have used a condom more than once $(n=429)$} \\
\hline Yes & 9 & 2.1 \\
\hline No & 420 & 97.9 \\
\hline \multicolumn{3}{|l|}{ Have used a lubricant with condoms $(n=427)$} \\
\hline Yes & 40 & 9.4 \\
\hline No & 387 & 90.6 \\
\hline \multicolumn{3}{|l|}{ Have experienced condom tear $(n=429)$} \\
\hline Yes & 55 & 12.8 \\
\hline No & 374 & 87.2 \\
\hline \multicolumn{3}{|l|}{ Response to condom tear $(n=55)$} \\
\hline Stopped sexual act & 5 & 9.1 \\
\hline Continued after using a new condom & 34 & 61.8 \\
\hline Continued without condom & 16 & 29.1 \\
\hline \multicolumn{3}{|l|}{ Had sex during menses $(n=431)$} \\
\hline Yes & 128 & 29.7 \\
\hline No & 303 & 70.3 \\
\hline \multicolumn{3}{|l|}{ Used condom for sex during menses $(n=128)$} \\
\hline Yes & 45 & 35.1 \\
\hline No & 79 & 61.7 \\
\hline No answer & 4 & 3.1 \\
\hline \multicolumn{3}{|l|}{ Group sex ${ }^{a}$} \\
\hline Have had group sex $(n=431)$ & 33 & 7.7 \\
\hline Used condom during group sex $(n=33)$ & 7 & 21.2 \\
\hline
\end{tabular}

${ }^{a}$ Having sex with more than 1 partner at the same time.

one-third continued sexual relations without a new condom. Similar findings were reported in a study conducted in Singapore [21].

An additional risk factor for HIV infection, as shown by a study on FSWs in Thailand, is having sex during menses [24]. With the shedding of the uterine mucosal lining, numerous blood vessels are open to receive the virus if the male partner is infected with HIV [24]. Sex during menses was of condom use, may be explained by the low prevalence of HIV infection in FSW' communities and clients. In a study in India, which covered different districts, the prevalence of HIV infection showed a large inter-district variation ranging from $2 \%$ to $38 \%$ which correlated with the prevalence of infection among clients in the different districts [15].

The zero prevalence of HIV infection among our participants indicates a low prevalence of HIV infection in spite of the observed risky behaviours for infection. This indicates that the potential HIV epidemic may be in the first stages among this most at-risk population and it could be a golden opportunity for intervention programmes to be implemented to limit its spread among sex workers and their clients.

\section{Limitations of the study}

There are two noteworthy limitations regarding the present study. The first concerns the nature of this research; this study focused on a very sensitive subject, with much stigma attached to it, which has not previously been studied in Egypt. Clearly, this represents a challenging task for research. As such, the research was limited in scope and aimed mainly to generate knowledge for further research. The second limitation has to do with the generalizability of the findings beyond the cases studied. Give the very specific group of participants the extent to which the results can be generalized to a wider population is limited. FSWs in our study and almost twothirds of them did so without using condoms.

The prevalence of HIV infection among FSWs in Greater Cairo was $0 \%$. A similar finding was found among FSWs in Santiago, Chile, which was attributed to high compliance of condom use among them [22]. In our study, however, this low prevalence of HIV infection, despite a low rate

\section{Conclusion}

FSWs in Greater Cairo are exposed to different factors that put them at high risk of HIV infection. These factors include: alcohol intake, drug abuse, physical violence, inadequate use of protective measures, questionable self-efficacy in using condoms, 
and an additional risk of having sex during menstruation. These risk factors urgently require more focused HIV-related health research, and highly specific long-term intervention programmes.

\section{Acknowledgements}

The authors express their thanks and appreciation to Dr Mervat El-Gueneidy, Professor of Neuropsychiatric Nursing at the University of Alexandria for her help. We thank all the women who participated in our study and those who helped by referring us to others. We also thank El-Shehab organization for its help in conducting this study.

\section{References}

1. Sarkar K et al. Epidemiology of HIV infection among brothelbased sex workers in Kolkata, India. Journal of Health, Population, and Nutrition, 2005, 23:231-235.

2. UNAIDS guidance note on HIV and sex work. Geneva, Joint United Nations Programme on AIDS (UNAIDS), 2009-2012.

3. AIDS epidemic update, 2009. Geneva, Joint United Nations Programme on HIV/AIDS (UNAIDS) and World Health Organization, 2009.

4. Abu-Raddad L et al. Characterizing the HIV/AIDS epidemic in the Middle East and North Africa: time for strategic action. Washington DC, World Bank, 2010 (http://www-wds.worldbank. org/external/default/WDSContentServer/WDSP/IB/2010/ 06/04/000333038_20100604011533/Rendered/PDF/5488 90PUB0EPI11C10Dislosed061312010.pdf, accessed 12 August 2012).

5. AIDS epidemic update 2005. Geneva, Joint United Nations Programme on HIV/AIDS and World Health Organization, 2005.

6. Buckingham RW, Webb N. Condom use among the female sex worker population in Thailand. International Journal of STD \& AIDS, 2004, 15:210-211.

7. $100 \%$ Condom Use Programme in entertainment establishments. Manila, World Health Organization Regional Office for the Western Pacific, 2000.

8. Wolffers I, van Beelen N, Brussa L. Violence, repression and other health threats. Sex workers at risk. Research for sex work, 2001, 4:1-32

9. UNAIDS Report on the global AIDS epidemic 2010. Geneva, Joint United Nations Program on HIV/AIDS (UNAIDS), 2010.

10. Rohaa SM, Hafez Y. Monitoring urbanization growth in Cairo City. Journal of Engineering and Applied Sciences, 2002, 49:667679.

11. Amon J et al. Behavioral surveillance surveys: Guideline for repeated behavioral surveys in populations at risk for HIV. Durham, NC, Family Health International, 2000:210-230.

12. World Health Organization. WHO global status report on alcohol 2004. Eastern Mediterranean for Region. Country profiles: Egypt (http://www.who.int/substance_abuse/publications/en/egypt.pdf, accessed 10 July 2012).

13. Illicit drug market in Greater Cairo. Cairo, United Nations Office for Drug Control and Crime Prevention, Regional Office for the
Middle East and North Africa, 2001 (Technical report on drugs and crime in North Africa and the Middle East).

14. Ward HD et al. Prostitution and risk of HIV: female prostitutes in London. British medical journal, 1993, 307:356-358.

15. Ramesh BM et al. Determination of HIV prevalence among female sex workers in four south Indian states analysis of cross-sectional surveys in twenty-three districts. AIDS (London, England), 2008, 22(Suppl. 5):S35-S44.

16. Mahfoud Z et al. HIV/AIDS among female sex workers, injecting drug users and men who have sex with men in Lebanon: results of the first biobehavioral surveys. AIDS (London, England), 2010, 24(Suppl. 2):S45-S54.

17. Shannon K, Csete J. Violence, condom negotiation, and HIV/ STI risk among sex workers. Journal of the American Medical Association, 2010, 304(5):573-574.

18. Renzaho A, Pallotta-Chiarolli M. Commercial sex work, survival sex, sexual violence and HIV/AIDS prevention in Arumeru District, Arusha Region of Tanzania. Open Tropical Medicine Journal, 2009, 2:27-38.

19. Da Ros CT, da Silva Schmitt C. Global epidemiology of sexually transmitted diseases. Asian Journal of Andrology, 2008, 10:110-114.

20. Barrientos JE et al. Prevalencia del VIH, conocimientos sobre el SIDA, y uso del condón en trabajadoras sexuales de Santiago, Chile [HIV prevalence, AIDS knowledge, and condom use among female sex workers in Santiago, Chile]. Cadernos de saúde pública, 2007, 23:1777-1784.

21. Vall-Mayans M et al. Sexually transmitted Chlamydia trachomatis, Neisseria gonorrhoeae, and HIV-1 infections in two at-risk populations in Barcelona: female street prostitutes and STI clinic attendees. International Journal of Infectious Diseases, 2007, 11:115-122.

22. Bruckova M et al. Short report: HIV infection among commercial sex workers and injecting drug users in the Czech Republic. American Journal of Tropical Medicine and Hygiene, 2006, 75:1017-1020.

23. Wee $\mathrm{S}$ et al. Determinants of inconsistent condom use with female sex workers among men attending the STD clinic in Singapore. Sexually Transmitted Infections, 2004, 80:310-314.

24. Kilmarx PH et al. HIV-1 seroconversion in a prospective study of female sex workers in northern Thailand. AIDS (London, England), 1998, 12:1889-1898. 